\title{
Examining dielectric properties of paper ageing in scrapped transformers
}

\author{
Asmaa Badr ${ }^{1}$, Loai Nasrat ${ }^{1}$, Abdulla Ibrahim ${ }^{1}$ \\ Electrical Engineering Department, Faculty of Engineering, Aswan University, Aswan, Egypt ${ }^{1}$
}

\begin{abstract}
Experimental Study of degradation of oil impregnated paper has attracted enormous attention over the past 20 years worldwide. Outside the controlled conditions of the laboratory, however the real situation is more complex due to loading change, ambient temperature, fluctuation and sudden impulse impact. Therefore, interests in forensic examinations of scrapped old transformers have increased in recent years since it may be a way to obtain under-service ageing information and connecting the laboratory ageing experiment with the reality. This paper presents the effect of ageing on the breakdown voltage and examines the effect of oil quality on the breakdown voltage of the paper. Tests results of service-aged papers taken from three failed power transformers. The result indicated that ageing has a small reduction effect on the breakdown voltage, whereas the breakdown voltage is affected more by the density of the paper and the quality of the oil.
\end{abstract}

Keywords: Dielectric measurements, FCA, DGA

\section{INTRODUCTION}

Paper and pressboard are one of the basic insulation materials used in the oil filled transformers. The good electrical and thermal properties are one of the advantages of these materials [1]. Paper is usually used to wrap the winding conductors. It is known that under large oil gap, the breakdown could occur at a lower voltage due to the fact that the probability of finding weakest spot will be high. This effect is also known as volume effect [2].Pressboard is used as spacer and barrier to divide the oil volumes into smaller oil gaps in order to enhance the dielectric strength of oil gaps. Therefore the key property of a pressboard as electrical insulation is its dielectric strength [1].

Both paper and pressboard are made from cellulose. One of the drawbacks of cellulose insulation is that the ageing is irreversible. Pressboards are gradually aged due to thermal stress, moisture and acidity; as the paper ages the transformer performance could be affected. For example, local carbonizing of the paper increases the conductivity to cause overheating which leads to conductor fault and brittle paper can break away from the winding and block the ducts [3, 4]. Furthermore, the byproducts of paper ageing such as water and acid also could accelerate the degradation of the paper.

It is important to monitor the condition of the paper to avoid catastrophic failure of a transformer. Mechanical strength measurement is the best technique to determine the ageing state of the paper since only this property is affected by ageing and not electrical and other properties [5]. However, it is impossible to obtain paper samples from in service transformers. Therefore, non intrusive techniques are used to determine the condition of the paper by measuring by products of paper ageing from the oil such as Furanic Compound Analysis (FCA) and Dissolve d Gas Analysis (DGA). However, interests in forensic examinations of scrapped old transformers have increased in recent years since it could provide the ultimate 'underservice' ageing information.
In this paper, the dielectric parameter including the ac breakdown voltage of the insulation papers in three scrapped power transformers impregnated in two different oil were examined and compared with each other.

\section{PAPER SAMPLING PROCEDURE}

All paper samples used for this investigation were taken during the scrapping procedure of three power Transformers. All paper samples were taken from the high voltage windings in each transformer. first The samples were cut into circular size with a diameter of $50 \mathrm{~mm}$ and were conditioned under room temperature and a relative humidity of about $55 \%$ for 24 hours; then dried in an aircirculating oven at $105^{\circ} \mathrm{C}$ for 48 hours and in a vacuumoven at $105^{\circ} \mathrm{C}$ and about 7 mbar for a further 24 hours. The oil-impregnation was performed with dried and degassed transformer mineral oil under vacuum at $80^{\circ} \mathrm{C}$ for a further 48 hours, according to BS/IEC 60641-2 (2004) [6]. The properties of aged papers can be seen in table 1.New paper was used to compare with the service aged papers. The density of new paper was $0.66 \mathrm{~g} / \mathrm{cm} 3$

Table 1 Properties of paper used for breakdown test.

\begin{tabular}{c|c|c|c}
\hline transformer & 1 & 2 & 3 \\
\hline $\begin{array}{c}\text { Service age } \\
\text { (years) }\end{array}$ & 45 & 33 & 37 \\
\hline Rated power & $\begin{array}{c}300 \\
\text { KVA }\end{array}$ & $\begin{array}{c}200 \\
\text { KVA }\end{array}$ & $\begin{array}{c}100 \\
\text { KVA }\end{array}$ \\
\hline $\begin{array}{c}\text { Thickness of paper } \\
(\mathrm{mm})\end{array}$ & 0.237 & 0.053 & 0.086 \\
\hline $\begin{array}{c}\text { Apparent density } \\
\left(\mathrm{g} / \mathrm{cm}^{3}\right)\end{array}$ & 0.76 & 0.76 & 1.17 \\
\hline
\end{tabular}

\section{EXPERIMENTATION}

Measurements were performed on impregnated paper samples in a controlled-moisture environment at room temperature. The first part of the study began with tests on paper samples impregnated with new oil. The second part 
of the experiment involved paper samples impregnated with aged oil to assess the influence of the oil condition on the dielectric properties of the paper. Shell Diala D was the oil used for impregnation. The aged and new oil were first filtered and dried before using. Table 2 gives the results obtained from the oil analysis and a comparison between the new and aged oil.

Table 2 oil characterization

\begin{tabular}{c|c|c}
\hline & new oil & aged oil \\
\hline Dielectric strength $(\mathrm{kV} / 2 \mathrm{~mm})$ & 39.63 & 38.63 \\
\hline Acidity $(\mathrm{mg} \mathrm{KOH} / \mathrm{g}$ of oil) & 0.001 & 0.22 \\
\hline Interfacial tension $(\mathrm{mN} / \mathrm{m})$ & 45.1 & 22.3 \\
\hline
\end{tabular}

\subsection{AC BREAKDOWN VOLTAGE TEST}

The ac breakdown voltage was measured according to ASTM D 149 using two electrodes which were $25 \mathrm{~mm}$ diameter brass cylinder types [7]. A single phase auto trans- former having a $5 \mathrm{kVA}-100 \mathrm{kV}-50 \mathrm{~Hz}$, Terco type HV 9105, has been used.

The circuit was set up as per figure 1 and a water resistor was used to limit the current.

For each test, five oil impregnated paper samples were tested, and the average value was calculated. The voltage was applied at a rise rate of $2 \mathrm{kV} / \mathrm{s}$ until breakdown occurs

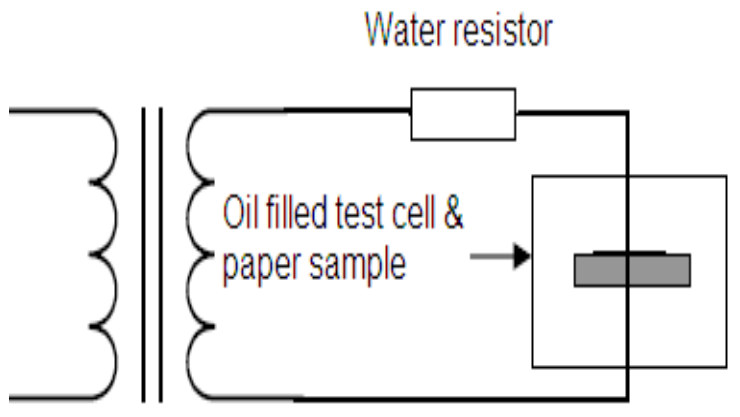

Figure1. Schematic diagram of breakdown voltage test

\section{RESULTS AND DISCUSSION}

Breakdown voltage test results of the service aged paper impregnated in new oil are shown in figure 2.

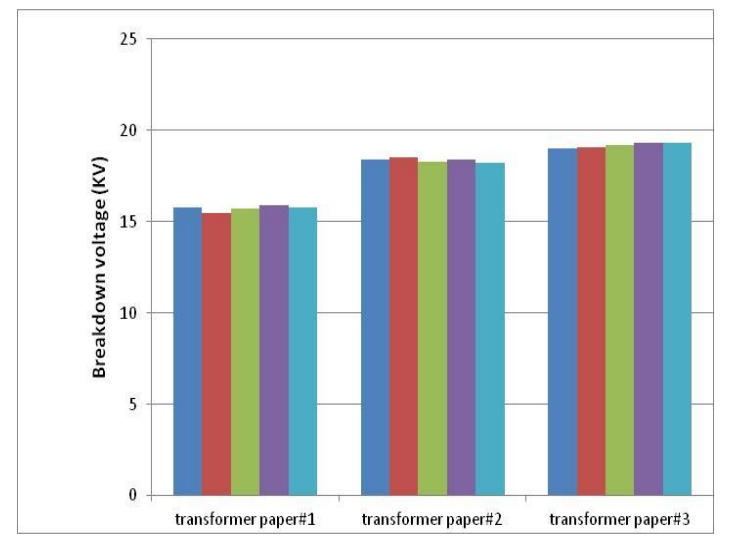

Figure 2.Breakdown voltage of service aged paper impregnated in new oil
Before discussing the significance of these results, it is interesting to compare the above data with the results of virgin oil-impregnated transformer paper in the table 3

Table 3.Breakdown voltage test results of new paper impregnated in new oil

\begin{tabular}{c|c}
\hline Sample Nr. & Breakdown voltage (KV) \\
\hline 1 & 15.6 \\
\hline 2 & 15.5 \\
\hline 3 & 15.5 \\
\hline 4 & 15.2 \\
\hline 5 & 15.5 \\
\hline
\end{tabular}

It is observed that the breakdown voltage for service aged paper in transformer \#3 is higher than both other service aged papers and new paper as seen in Figure 2 and table 3. These results show that the ageing of paper has a different density has no effect on the breakdown voltage of these paper. It is interesting to note that there are some similar reports on ageing effects on the dielectric characteristics of pressboard insulation in the literature. For example, in laboratory accelerated aged paper where the breakdown strength of the paper remains almost unchanged even after 6 months of ageing at $120{ }^{\circ} \mathrm{C}$ [8]. It is found that density has a significant effect on the breakdown voltage of the paper regardless of ageing years as shown in Figure 3. Service aged paper in transformer\#3 has the highest breakdown voltage followed by transformer paper\#2 then transformer paper\#1 and finally the new paper.

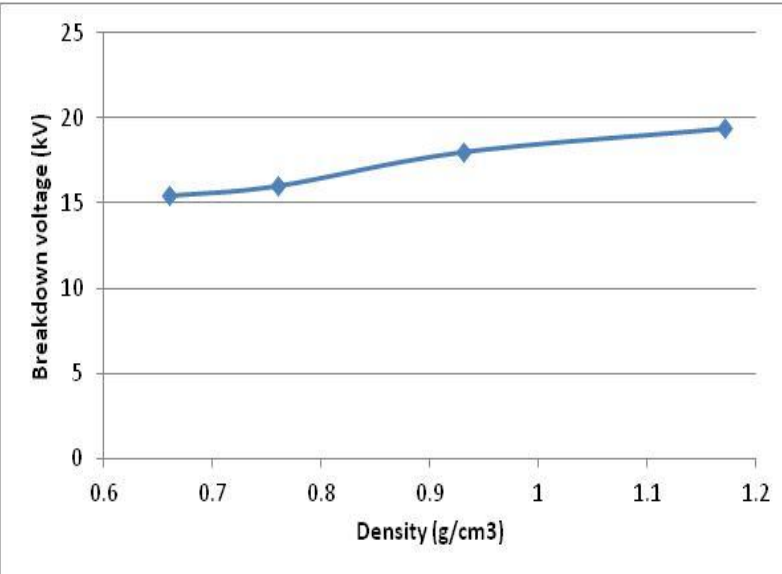

Figure 3.Relationship between breakdown voltages of paper impregnated in new oil and Density

The result is in line with previous finding where the breakdown voltage is high for paper with a high density [9]

In order to look into the effect of oil quality on the breakdown voltage of the paper, similar of above service aged paper and new paper samples were impregnated in aged oil and the breakdown voltage results were recorded and compared. 
For service aged paper impregnated in aged oil, it is These results show that the oil quality could affect the observed that the reduction of breakdown voltage overall performance of breakdown voltage of oil/paper

increases ranging from $7 \%$ to $10 \%$ as seen in Figure 4.

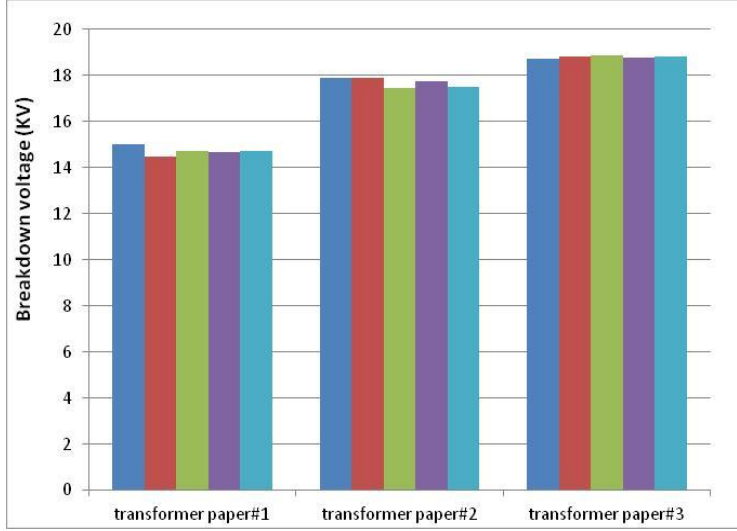

Figure 4.Breakdown voltage of service aged paper impregnated in aged oil.

and for the new paper impregnated in aged oil the reduction of breakdown strength can be seen in table 4 .

Table 4. Breakdown voltage test results of new paper impregnated in aged oil

\begin{tabular}{c|c}
\hline Sample Nr. & Breakdown voltage (KV) \\
\hline 1 & 14.5 \\
\hline 2 & 14.4 \\
\hline 3 & 14.5 \\
\hline 4 & 14.4 \\
\hline 5 & 14.3 \\
\hline
\end{tabular}

Figure 5 shows the comparison between breakdown strengths of paper impregnated in new and aged oil. Similar trend is observed for all types of paper, that paper impregnated in aged oil suffers around $7 \%$ to $10 \%$ reduction of breakdown strength.

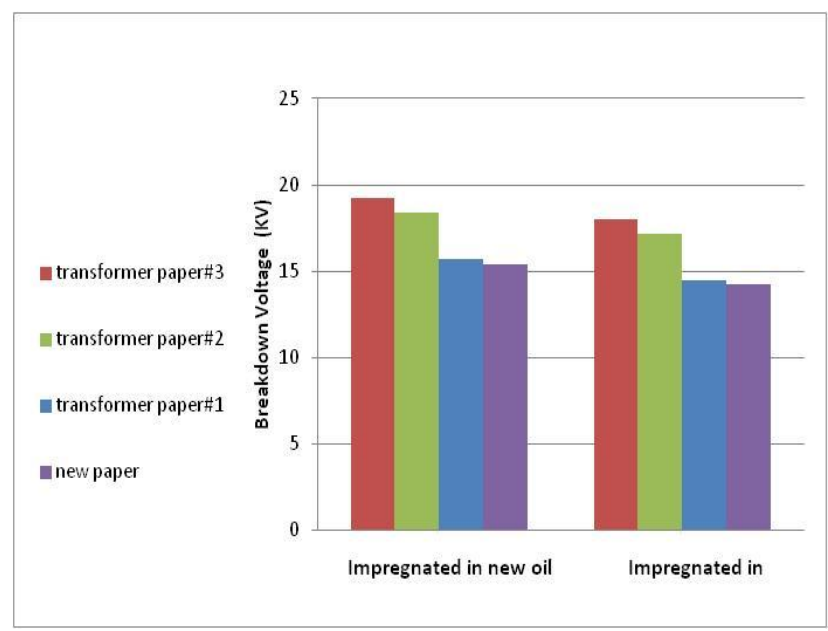

Figure 5.Average breakdown voltage of new and service aged paper.

\section{CONCLUSION}

This study has focused on the effect of ageing and the oil quality effect on the breakdown strength of oilimpregnated paper. These dielectric measurements conducted on service aged paper and new paper with different impregnation oils lead to the following conclusions:

- It is observed that ageing does not bear any relationship with the breakdown strength of the paper of different density.

- It is found that density has a significant effect on the breakdown voltage of the impregnated paper.

- Oil condition could influence the dielectric breakdown voltage of the paper.

It is difficult to determine the ageing status of the paper based on electrical property since paper can maintain its electrical performance under ageing conditions.

\section{ACKNOWLEDGMENT}

The authors wish to thank the staff in workshop of Upper Egypt Electrical Distribution Company.

\section{REFERENCES}

[1] H. P. Moser and V. Dahinden. Transformerboard II. H.Weidmann AG, CH-8640 Rapperswil, 1987.

[2] W. R. Wilson, "A fundamental factor controlling the unit dielectric strength of oil," AIEE Trans. Power App. Syst., vol. 72, pp. 68-74, 1953.

[3] R. J. Heywood, A. M. Emsley and M. Ali, "Degradation of cellulosic insulation in power transformers part I: factors affecting the measurement of the average viscometric degree of polymerisation of new and aged electrical papers," IEE Proceedings on Science, Measurement and Technology, vol. 147, pp. 86-90, 2000.

[4] A. M. Emsley and G. C. Stevens, "Review of chemical indicators of degradation of cellulosic electrical paper insulation in oil-filled power transformers," IEE Proceedings on Science, Measurement and Technology, vol. 141, 1994.

[5] H. Yoshida, Y. Ishioka, T. Suzuki, T. Yanari and T. Teranishi, "Degradation of insulating materials of transformers," Electrical Insulation, IEEE Transactions on, vol. EI-22, pp. 795-800, 1987.

[6] BS/IEC 60641-2 (2004): Pressboard and presspaper for electrical purposes-part 2: methods of tests.

[7] ASTM D149-97a (Reapproved 2004) "Standard Test Method for Dielectric Breakdown Voltage and Dielectric Strength of Solid Electrical Insulating Materials at Commercial Power Frequencies".

[8] T. S. R. Murthy, U. Yugandhar, S. C. Gupta, A. Bhoomaiah and J. S. Kuntia, "Study on the effect of impulse voltage withstandability on the thermally-aged transformer paper," in Electrical Insulation, 2004. Conference Record of the 2004 IEEE International Symposium on, 2004, pp. 38-41.

[9] J. Dai, "Studies on failure mechanisms of transformer cellulose insulation with consideration of ester oil application," $\mathrm{PhD}$ thesis in Electrical and Electronic Engineering, 2009. 